\title{
Evaluation of the simultaneous production of lutein and lipids using a vertical alveolar panel bioreactor for three Chlorella species
}

\author{
Blanca Araya ${ }^{\mathrm{a}, \mathrm{b}}$, Luísa Gouveia ${ }^{\mathrm{c}}$, Beatriz Nobre ${ }^{\mathrm{c}}$, Alberto Reis ${ }^{\mathrm{c}}$, Rolando Chamy ${ }^{\mathrm{a}, \mathrm{b}}$, Paola Poirrier ${ }^{\mathrm{a}, \mathrm{b}, *}$ \\ a Escuela de Ingeniería Bioquímica, Pontificia Universidad Católica de Valparaíso, Chile \\ ${ }^{\mathrm{b}}$ Fundación Fraunhofer Chile Research, Chile \\ c LNEG I.P., Unidade de Bioenergia, Estrada do Paço do Lumiar, 22, 1649-038 Lisbon, Portugal
}

\section{A R T I C L E I N F O}

\section{Article history:}

Received 2 December 2013

Received in revised form 5 June 2014

Accepted 9 June 2014

Available online 4 July 2014

\section{Keywords:}

Lutein

Lipid

Photoautotrophic growth

Vertical alveolar panel photobioreactor

Chlorella sp.

Cell disruption

\begin{abstract}
A B S T R A C T
The concept of a biorefinery improves the economic efficiency of a biofuel production process from microalgae by recovering high value added compounds. Lutein is a carotenoid currently extracted from petals of Tagetes erecta with an established market in poultry and in human nutritional supplements. For the very first time, an extended study on the lipid and lutein production over three Chlorella species as well as cell disruption methods was performed. Chlorella vulgaris, Chlorella zofingiensis and Chlorella protothecoides were grown in an indoor vertical alveolar panel photobioreactor with continuous illumination, and two cell disruption methods were assessed at a laboratory scale: glass bead vortexing and ball mill grinding. For C. vulgaris, C. zofingiensis and C. protothecoides the intracellular lutein content was measured as: $3.86,4.38$ and $3.59 \mathrm{mg} \mathrm{g}^{-1}$ respectively. Lipid contents vary slightly among microalgae with a value close to $9 \% \mathrm{w} / \mathrm{w}$. Biomass and lutein productivities were found to be higher for C. vulgaris $\left(0.131 \mathrm{gL}^{-1} \mathrm{~d}^{-1}, 0.51 \mathrm{mg} \mathrm{L}^{-1} \mathrm{~d}^{-1}\right)$ and for C. zofingiensis $\left(0.122 \mathrm{gL}^{-1} \mathrm{~d}^{-1}, 0.53 \mathrm{mg} \mathrm{L}^{-1} \mathrm{~d}^{-1}\right)$ compared to $C$. protothecoides $\left(0.103 \mathrm{gL}^{-1} \mathrm{~d}^{-1}, 0.37 \mathrm{mg} \mathrm{L}^{-1} \mathrm{~d}^{-1}\right)$.

C. vulgaris 1803 and C. zofingiensis B 32 were found to be promising organisms for simultaneous production of lutein and lipids. Although all the microalgae under study belong to the same genus, a species-specific response was observed for each of the cell grinding methods tested.
\end{abstract}

(c) 2014 Elsevier B.V. All rights reserved.

\section{Introduction}

In the last decade, biofuel production from microalgae has been intensively investigated. This is evident by the rapidly increasing number of research articles published and patents issued [1]. A number of advantages of microalgae over conventional oilseed crops explain this research effort: fresh water consumption can be reduced using wastewater or seawater microalgae; its production does not require agricultural land and a high biomass and oil productivity per acre can be attained [2,3]. A theoretical ceiling of 94 to $155 \mathrm{~m}^{3}$ oil ha $^{-1} \mathrm{yr}^{-1}$ was calculated for microalgae assuming oil contents of $25 \%$ or $50 \%$ respectively [4] and a 10\% photosynthetic efficiency [5]. Although these figures represent a theoretical value, when a realistic lipid productivity is considered (cf. supplementary material in ref. [4]), oil productivity of microalgae culture is still 4.65 and 23.4 times higher when compared to palm or sunflower oil productivities [3]. However, using realistic productivities, biofuel production can only be economically feasible when high value products are concomitantly produced [4]. A biorefinery approach in which both fuels and multiple value-added

\footnotetext{
* Corresponding author at: Pontificia Universidad Católica de Valparaíso, Chile. Tel.: +5632 2273655

E-mail address: paola.poirrier@ucv.cl (P. Poirrier).
}

compounds are produced, or even microalgae production is synergistically coupled with carbon sequestration and wastewater treatment [6], might support the development of the microalgae energy industry. The potential for valuable co-products in algae processing has been cited as one of the key reasons for exploring this source of biofuels [7]. Besides polar and non-polar lipids, microalgae produce pigments and sterols with established market values $[1,8]$. Among the colored compounds, carotenoids are lipid-soluble molecules that play essential roles in photosynthesis. They contribute to light harvesting, scavenge reactive oxygen species and dissipate excess energy [9].

Lutein, a carotenoid found in flowers, food and human serum [10] has also been reported to be available in microalgae [11], has an established market in poultry and human nutritional supplements with a world market valued at 233 million USD in 2010 [12]. Along with zeaxanthin, lutein is present in the macula lutea, a small area in the retina [13] and in the crystalline lens [14]. Oral intake of lutein has been linked to a reduced risk of diseases such as age related macular degeneration [13,15], cataracts [16-18] and retinal degeneration [19].

Currently, the lutein production process involves the extraction of this compound from dried Tagetes sp. petals with organic solvents, saponification of the extract to remove waxes and fatty acids, and finally crystallization [20]. The product contains lutein as the major component and a smaller proportion of zeaxanthin. Lutein production from petals is 